\title{
Salazar-Knowles Equation Parameter A
}

National Cancer Institute

\section{Source}

National Cancer Institute. Salazar-Knowles Equation Parameter A. NCI Thesaurus. Code C139256.

A representation of the exponential function described by the Salazar-Knowles equation, and an estimation of a subject's inspiratory capacity. 